Archivum, LXXI, 2021, pp. 433-474

\title{
El lenguaje interdisciplinar en las ciencias humanas e históricas: teoría para una guía de estilo y una distinción del sentido figurado
}

\author{
Álvaro Pina Arrabal \\ Universidad de JAÉN \\ pina.arrabal@gmail.com
}

Recibido: 04/04/2021

Aceptado: 09/08/2021

\section{RESUMEN:}

En este trabajo se plantea la posibilidad de confeccionar una guía de estilo, basada en el empleo de un lenguaje interdisciplinar, para las ciencias humanas e históricas. En primer lugar, se considera la clasificación de las ciencias elaborada de modo reciente por David Alvargonzález (2019-2020) a partir de la teoría del cierre categorial del filósofo Gustavo Bueno. Se concibe 'lo científico' como una parte constitutiva esencial de 'lo académico', que comprende actividades como la divulgación científica o la enseñanza. En segundo lugar, se revisa la noción de lenguaje figurado en cuanto que tautológica: entendiendo que todos los usos del lenguaje son, en realidad, figurados, se propone una nueva distinción - más rigurosa a efectos terminológicos-para designar la tradicional diferencia entre el sentido recto y el figurado: figuración matriz $o$ de primer grado y figuración radial $o$ de segundo grado. A partir de esta última, y en relación con la idea de intermultidisciplinariedad, se proyecta un inventario en el 
que se recojan unidades léxicas de especialidad cuyos usos figurados de segundo grado resulten aprovechables en el discurso de las ciencias humanas e históricas.

PALABRAS CLAVE: Divulgación científica, estilo académico, gnoseología, lenguaje figurado, léxico intermultidisciplinar, metáfora

\title{
Interdisciplinary Language in Human and Historical Sciences: Theory for a Style Guide and a Distinction of Figurative Sense
}

\begin{abstract}
:
In this work, we contemplate the possibility of preparing a style guide, based on the use of an interdisciplinary language, for human and historical sciences. In the first place, we consider the classification of sciences recently elaborated by David Alvargonzález (2019-2020), who has taken the philosopher Gustavo Bueno's theory of categorial closure as a point of departure. 'The scientific' is conceived as an essential constitutive part of 'the academic', which comprises activities such as scientific dissemination or teaching. In the second place, the notion of figurative language is examined insomuch as it is tautological: assuming that all the usages of words are, indeed, figurative, a new distinction-terminologically more rigorous-is proposed in order to designate the traditional difference between literal and figurative sense: original or first-degree figurative language and extended or second-degree figurative language. Considering the latter in relation with the idea of intermultidisciplinarity, we plan an inventory which gathers specialty lexical units whose second-degree figurative usages may be productive for the discourse of human and historical sciences.
\end{abstract}

KE YWORDS: Scientific dissemination, academic style, gnoseology, figurative language, intermultidisciplinary lexis, metaphor

\section{Introducción}

El empleo del denominado sentido figurado en el lenguaje científico ha sido objeto de estudio en numerosas ocasiones. Sin embargo, no existe aún un consenso unánime acerca de su idoneidad: mientras que algunos autores apelan al imperativo de objetividad en la ciencia para evitar su uso, muchos otros lo legitiman como una "herramienta de pensamiento" (de la Torre, 2003, 99); afirmar, por ejemplo, que el bosón de Higgs es una 'excitación del vacío' constituye un uso metafórico mediante el 
que se intenta explicar un fenómeno no del todo conocido en el campo de la física de partículas. La publicación en 2016 del Diccionario bilingüe de metáforas y metonimias científico-técnicas resulta elocuente de la amplia presencia en el lenguaje científico de lo que aquí se propondrá referir, para mayor concreción, como 'figuración de segundo grado' (véase apartado 3.1.).

El objetivo último de este trabajo es plantear una guía de estilo basada en el uso de léxico interdisciplinar para las ciencias humanas e históricas, por lo que se antoja necesario delimitar primero los fundamentos de la misma. Se incluyen dos apartados en los que se desarrollan las dos cuestiones principales que cimientan la propuesta: la clasificación de las ciencias $-\mathrm{y}$, en particular, la noción de ciencias humanas- y la pertinencia del precitado sentido figurado en el lenguaje científico. En ambos casos se manejan conceptos e ideas que permitan proyectar, en última instancia, la mencionada guía o inventario (en el sentido de un catálogo o repertorio de léxico científico interdisciplinar). Así, se plantea la posibilidad de utilizar, en las ciencias humanas e históricas, terminología técnica de otros campos con fines de enriquecimiento discursivo e, incluso, de matización y concreción epistemológica y/o gnoseológica (entendiendo por gnoseología la teoría del conocimiento científico, basada en la oposición forma-materia; y por epistemología la teoría de un conocimiento más general -menos categorizado-, basada en la oposición sujeto-objeto [Bueno, 2012]). No por casualidad, como subraya Galán (2001, 133), "los grandes saltos cualitativos en la ciencia han tenido siempre mucho que ver con el poder de las metáforas para generar intuiciones transformadoras de los paradigmas epistémicos establecidos". A continuación, se abordan los puntos citados con el fin de establecer ciertas bases teóricas para la confección de la hipotética guía. 


\section{Las ciencias humanas e históricas}

\subsection{Historia y clasificación}

Se han escrito ríos de tinta acerca de qué es la ciencia y qué áreas la integran. Se trata de un tema de largo recorrido, pues ya en época clásica Aristóteles ofreció una explicación teleológica -esto es, basada en las causas finales- de la investigación científica (Mardones, 2001, 21-23). Un error relativamente común es tomar la palabra de autores inveterados como si fuera divina (falacias ad antiquitatem y ad verecundiam): es poco probable que lo razonado en la Antigua Grecia hace más de dos mil años pueda dar cuenta exacta de las especificidades que la ciencia actual sí alcanza. Considérense, por ejemplo, la tecnología, que hubiera sido tomada por magia en época clásica (del mismo modo que hoy la magia encuentra su explicación más inmediata en la tecnología), o la incierta idea aristotélica, cuestionada en el siglo XX por filósofos como Hempel o Russell, de que la ciencia sigue un proceso de inducción desde las observaciones particulares hasta los principios generales. El propósito de conocer las causas mediante la ciencia es modificar la realidad, no imitarla como si de un hecho apriorístico e inamovible se tratara (tal y como se desprende del principio aristotélico de mímesis). Tampoco cabe incurrir, en cualquier caso, en una desacreditación exacerbada de todas las teorías pasadas, dado que muchas son precursoras de las actuales y algunas incluso mantienen cierta vigencia en la actualidad.

Por otro lado, la casuística del tema se ha visto incrementada con el tiempo, a partir tanto del desarrollo de las ciencias como de la ingente cantidad de clasificaciones que se han ido realizando en paralelo. Es, en particular, en los siglos XIX y XX cuando se genera toda una maraña organizativa de la que, precisamente, han quedado muchas de las nociones que se manejan en la actualidad. Desde el idealismo alemán de Hegel hasta Bunge, pasando por Engels, Windelband, Wundt, Ostwald u Oppenheim, entre tantos otros, se han aportado diversas clasificaciones de cien- 
cias -entendiendo clasificaciones en sentido laxo- que varían en número y agrupación, pero cuyos perímetros pueden ser más o menos reconciliables.

Rudolf Carnap (1935) distinguió -con un afán unificador de las ciencias tan monista como utópico- entre ciencias formales (lógicas y matemáticas) y factuales (naturales y culturales). Kedrov y Spirkin (1968) hablaron de ciencias filosóficas (dialéctica y lógica), matemáticas, naturales/técnicas (astronomía, física, química, mecánica, biología o geología) y sociales (historia, arqueología, economía, lingüística o psicología) (Saldivia, 2009). Jean Piaget (1970, 2-7) utilizó las etiquetas de ciencias nomotéticas (psicología, sociología, etnología, lingüística o economía), históricas, jurídicas y disciplinas filosóficas. Aclárese en este punto que, como ya resaltó Wittgenstein, la filosofía no es una ciencia (aunque la filosofía de la ciencia sí es, evidentemente, posible), por lo que una conceptualización tal como ciencias filosóficas -o similar- no procede. Si bien ambas, filosofía y ciencia, se encuentran a menudo próximas, la primera trabaja con ideas y la segunda con conceptos. Así, por ejemplo, la Teoría de la literatura es una ciencia y la crítica literaria es un ejercicio de raíz filosófica (Maestro, 2014, 51-52). La filosofía es un sistema no científico y, como tal, admite sus propias clasificaciones internas (véase la propuesta de Bueno, 2004).

Gustavo Bueno (1992, 196-201), en su Teoría del cierre categorial, admitió una clasificación en dos grupos: las ciencias naturales, que enmarcó en una situación $\alpha$ (sin presencia del sujeto gnoseológico), y las ciencias humanas, insertas a grandes rasgos en una situación $B$ (con presencia del sujeto gnoseológico). Dentro de estas últimas, no obstante, hizo una segunda distinción entre metodologías $\alpha$ y metodologías \& (más sus dos respectivas articulaciones), que -sin entrar en demasiados detalles- permitirían, por ejemplo, segregar en lingüística la fonética $\left(\alpha_{1}\right)$ y la fonología $\left(\alpha_{2}\right)$ de la lingüística aplicada o la enseñanza de idiomas $\left(\beta_{2}\right)$ (Bueno, $1978,44)$. En otro orden, las espuriamente denominadas ciencias positivas útiles (biología, química o geología, entre otras) forman 
parte de un grupo de ciencias categorialmente estrictas, mientras que las etiquetadas como ciencias positivas culturales (sociología o antropología, por citar dos) se encuentran categorialmente ampliadas.

Mucha menos consideración merecen términos, a menudo coloquiales, como ciencias puras, duras o blandas, no más rigurosos que la tradicional dicotomía -a todas luces falsa- entre 'Ciencias' y 'Letras': un busto de mármol, por citar un ejemplo, es una roca metamórfica con unas propiedades físicas de dureza, transparencia y densidad determinadas que, no obstante, ha sido tallada por un 'sujeto operatorio' (en terminología de Bueno) con unas coordenadas artísticas e históricas concretas, igualmente objetivables y categorizables desde un punto de vista científico. Las ciencias, como apunta David Alvargonzález $(2019,105)$, pueden operar mediante "signos auto-referentes" (las matemáticas) o no, lo que puede condicionar "la estructura de la ciencia" o el "grado de cientificidad", pero no la cualidad misma de ciencia.

Ha sido precisamente Alvargonzález $(2019,107)$ el último en plantear una clasificación de las ciencias desde la filosofía del cierre categorial de Bueno. En ella distingue cuatro tipos: formales, naturales, humanas/etológicas e históricas. Aunque, como el mismo autor señala, ya Lalande había elaborado a finales del siglo XIX una separación parecida a la suya, la verdadera cuestión atañe a los fundamentos de la clasificación, que se definen por "la estructura operatoria de los diferentes campos científicos" $(2019,107)$. Esto, como se ha indicado en el párrafo anterior, afecta al grado de cientificidad de cada campo, y es por lo tanto aquí donde cabe establecer las diferencias sistémicas entre unas ciencias y otras, con especial énfasis en las humanas e históricas de cara al objetivo del presente trabajo.

Siguiendo lo expuesto por Bueno en su Teoría del cierre categorial, Alvargonzález (2020, 34-36) arguye que hay cuatro modulaciones del cierre, una para cada ciencia. Así, mientras las ciencias naturales "presentan el cierre categorial canónico y representan la cientificidad estricta" en la medida en que se configuran de 
manera anantrópica (con independencia del sujeto gnoseológico), las humanas "exigen considerar las operaciones de los sujetos a la misma escala de su propia ejecución", es decir, hacen uso de las metodologías $ß$ teorizadas por Bueno. De igual modo, los sistemas técnicos (como un coche o un ordenador) tienen un carácter antrópico porque el sujeto interviene en su constitución, lo que, tal y como subraya Alvargonzález (2020, 30), los distingue de las ciencias. Dentro de estas, las naturales y las formales son las más alejadas de la técnica por ser aquellas en las que el sujeto no interviene en el cierre categorial al estar "el sistematismo [...] determinado por la estructura ontológica de la realidad" (Alvargonzález, 2020, 33). Así pues, como también indica el autor (2020, 36), "las ciencias humanas y etológicas ocuparían un lugar intermedio entre las ciencias estrictas y las técnicas puramente prácticas". Varía, en definitiva, el grado de cientificidad de los campos, pero no su condición de ciencia como tal.

En un orden cercano - pero no idéntico- al de las ciencias humanas queda la historia idiográfica, cuyo cierre categorial es ligeramente distinto por constituirse a partir de sucesos pasados de carácter irrepetible y que podría agruparse con las primeras en el marco de un término más amplio, que aquí se considerará menos preciso: Humanidades, un vocablo que se regulariza en el Renacimiento, cuando los studia humanitatis se convierten en un elemento básico del saber en oposición a las letras divinas. Se trata, sin embargo, de una categoría bastante heteróclita que da cabida tanto a las ciencias humanas e históricas como a diversas artes e, incluso, a la filosofía. Para dar cuenta de esta hiperhomogeneización y obliterar la amalgama, Jerzy Pelc $(1997,267)$ estableció una lúcida dicotomía entre "Humanidades científicas" y "Humanidades literarias". Como sus propios nombres indican, las primeras engloban "las consideraciones científicas" y tienen lugar en contextos universitarios -al menos sobre el papel- y científicos en general, mientras que las segundas comprenden un abanico mayor de artes e intercambios de ideas exentos de rigor científico, que se dan en forma de conferencias, debates en me- 
dios de comunicación o ensayos filosóficos, entre otros. Así, por ejemplo, la literatura es un arte y se adscribe a las Humanidades literarias, pero la Teoría de la literatura es una ciencia (ß operatoria, en términos de Bueno) y se enmarca en las Humanidades científicas.

Si bien la distinción entre unas Humanidades y otras es pertinente y no sería inviable plantear este trabajo a partir de la noción de Humanidades científicas, las características de esta última -más generales y de orden práctico que puramente científicas- hacen preferible cimentar la propuesta sobre el término de ciencias humanas. Por extensión, las ciencias históricas, aunque presentan algunas variaciones gnoseológicas con respecto a las humanas (Alvargonzález, 2019, 114), pueden unirse a estas últimas a efectos de lenguaje interdisciplinar proveniente de otros campos científicos, así como de otros sistemas técnicos (ingenierías) o doctrinales no filosóficos (Derecho, Teología). De este modo, la guía o inventario de léxico interdisciplinar que se propone para las ciencias humanas e históricas se nutriría tanto de las ciencias con un cierre categorial canónico (sin presencia del sujeto gnoseológico) como de otros sistemas no estrictamente científicos que, no obstante, operan a menudo con terminología técnica específica.

\subsection{La divulgación científica en el marco de 'lo académico'}

Una última puntualización atañe a la distinción, cada vez más confusa, entre 'lo académico' y 'lo científico'. Si la ciencia se compone, como se ha explicado, de una pluralidad de campos con mayor o menor grado de especificidad, lo académico se dispone en un perímetro más general, que puede estar relacionado con la enseñanza o la simple divulgación científica, entre otras posibilidades. Sobre esta última, Sánchez Mora $(2000,11)$ aclara: "la divulgación de la ciencia puede o no hacer énfasis en el método científico pero [...] los recursos de que echa mano pertenecen más a la literatura que a la ciencia". No en vano, como testifica Mancho Duque (2005), ya en la época del Quijote -y en el propio 
Quijote - se dan frecuentes ejercicios de divulgación científica en forma, sobre todo, de tecnicismos insertos en obras literarias como la de Cervantes.

En realidad, la divulgación científica es una extensión lógica de la propia ciencia en tanto en cuanto esta debe establecer una relación fluida con la sociedad que la posibilita. Llácer y Ballesteros $(2012,58)$ hablan de un "parto doble" de la ciencia moderna y la divulgación de la ciencia de la mano de Galileo Galilei, quien "comprendió que la ciencia debía llegar al máximo número de lectores". Debido al alto grado de especificidad que requieren los distintos campos científicos, los conceptos que en estos se manejan resultan ininteligibles para el grueso de la población. Por ello, la divulgación científica y, en definitiva, la cristalización de los resultados en aras de la sociedad han de ser claros y comprensibles para un público no especializado. Esto es relativamente sencillo en el caso de una ciencia como la medicina (la más fértil en metáforas, según Eurrutia [2003, 373]), en la que, a partir de fórmulas químicas con las que solo un especialista puede operar de manera adecuada, se logra producir un medicamento que redunda en beneficio de la población incluso si esta no es capaz de entender los procedimientos científicos que permiten la elaboración del fármaco. En el caso de las ciencias humanas, al no generarse normalmente un resultado corpóreo -aunque sí material, siguiendo la teoría de la materia de Gustavo Buenoel paradigma es diferente, pero no por ello dejan de producirse resultados transferibles a la sociedad. En una ciencia como la lingüística, por ejemplo, es posible parafrasear conceptos técnicos cualesquiera (verbigracia: diafásico, proxémico) por su significado correspondiente. Esto es lo que ocurre, sin ir más lejos, en el contexto académico de una clase, en la que el profesorado explica términos circunscritos al campo categorial correspondiente con fines docentes, esto es, de divulgación científica.

Es precisamente en este punto donde cabe establecer la referida distinción entre academicismo y cientificismo. Aquí se considerará 'lo científico' como un conjunto independiente que, 
no obstante, se integra a menudo dentro de 'lo académico'. En un instituto o una universidad se presupone que el alumnado adquirirá aquellos conocimientos científicos ya determinados, si bien no ejercerá necesariamente una labor de investigación científica más allá del contexto académico -de aprendizaje- en el que se desenvuelve. La falla de este propósito se hace patente cuando, como advierte Maestro (2020, 6:12-6:16), se produce una "deserción creciente de las ciencias del ámbito académico". En el momento en que el contenido científico $\left(\mathrm{M}_{3^{\prime}}\right.$ en el Materialismo Filosófico de Bueno) es reemplazado -que no compartidopor los sentimientos o emociones $\left(\mathrm{M}_{2}\right)$ que suscita el contenido científico en cuestión, este queda devaluado y malversado. La enseñanza no es el único contexto académico posible, pero sí es desde luego el más relevante a día de hoy y cabe, por lo tanto, ser críticos con el espacio real que la ciencia ocupa en la misma. Se trata, en fin, de ámbitos muy afines, hasta el punto de que lo académico pierde su razón de ser sin un sustrato científico mínimo y lo científico queda, en consecuencia, reducido a espacios de investigación minoritarios. A grandes rasgos, podría establecerse un par de correlaciones entre 'lo académico' y la epistemología (como teoría del conocimiento) y entre 'lo científico' y la gnoseología (como teoría del conocimiento científico).

\section{Figuración y lenguaje intermultidisciplinar}

\subsection{La falacia del 'lenguaje figurado' y su empleo en el ám- bito científico \\ Hay dos posturas principales en torno al uso del llamado lenguaje figurado en la ciencia: las que lo juzgan inconveniente, dado el carácter recto y objetivo que se presupone en el ejercicio científico, y las que ven en él una vía de aclaración y estructu- ración -cuando no de ampliación- del pensamiento. Al abordar de manera rigurosa esta cuestión, es imprescindible considerar una realidad a menudo preterida o ignorada: todos los usos de la lengua son figurados en la medida en que las palabras designan}


un referente (tenga capacidad operatoria o no, pues también un concepto abstracto se referencia mediante el lenguaje) y en que responden a un acuerdo entre sus usuarios (ya sean escritores o hablantes). Así como toda la literatura -incluso la autobiográfica- es ficción, todo el lenguaje -incluso el considerado como más literal- es figurado: la ontología general de una y otro es inmutable, aun cuando en ambas existen diversos grados y tipos (véanse los tropos, como la metáfora o la metonimia). Por extensión, como indica Ramón Trujillo (2004, 912-914), “las acepciones que registran los diccionarios no pueden ser sino usos figurados", pues no dejan de estar elaboradas por personas. El signo lingüístico es arbitrario y, por lo tanto, no hay ningún motivo más allá de la convención social por el que un adjetivo como redondo signifique tanto "de forma circular" como "perfecto, completo" (DRAE, 2019). Quizás no por casualidad, como también observa Trujillo $(2004,912)$, la Academia suprimió del DRAE-2001 la etiqueta de uso figurado.

La palabra en sí es -aplicando de nuevo los presupuestos del Materialismo Filosófico de Gustavo Bueno- una materia más, que se configura mediante dos posibles canales: la escritura y la oralidad. En el primer caso, se precisa de un soporte físico que posibilite la grafía de la palabra. En el segundo caso, la materialidad se da en forma de sonido, esto es, como la propagación de una perturbación en el aire que resulta cuantificable en términos físicos. Como explicaron Lakoff y Johnson (1999, 16-20), la razón y los procesos de cognición (las categorías del lenguaje, los conceptos) están inevitablemente determinados por lo corpóreo: el lenguaje no existe por sí solo de modo idealista, sino que se vehicula a través de seres humanos dotados de las cualidades sensoriomotoras necesarias para emplearlo. Así, por poner otro ejemplo, en español se utiliza la palabra libro para referirse a un conjunto de hojas encuadernadas, pero nada impide -más allá del mencionado pacto entre usuarios del idioma- que una persona designe como libro lo que se ha dado en llamar mesa, justicia o domótica. De darse esta última circunstancia, evidentemente se 
generarían más que probables dificultades de comprensión aun tratándose de usuarios de la misma lengua, pero hacerlo no atentaría contra lo que el lenguaje es en rigor científico, al margen de los usos sociales.

La (falsa) oposición entre lenguaje recto y figurado es, pues, una invención de las comunidades científicas, no un hecho espontáneo y natural del lenguaje (Neira, 1999, 161). El sintagma lenguaje figurado, normalmente concebido como opuesto al de lenguaje recto o literal, resulta así tautológico. Sin embargo, aun si se tiene conocimiento de que todos los usos son figurados, la mayoría de autores sigue utilizando esta terminología, acaso por pragmatismo comunicativo. Para evitar incurrir en esta situación, en el presente trabajo se propone una simple pero efectiva distinción entre un lenguaje figurado 'de primer grado', correspondiente al tradicionalmente conocido como sentido recto; y un lenguaje figurado 'de segundo grado', equivalente al hasta ahora redundantemente denominado lenguaje figurado. La novedad de esta separación con respecto a, por ejemplo, la referida por Trujillo $(2014,914)$ de "variantes fundamentales" frente a "variantes libres" radica en que los conceptos mismos objetivan la figuración como un hecho inherente a todo uso lingüístico. Ha de quedar claro que esta diferenciación es puramente terminológica: no cambia el fondo de los elementos (los tradicionales sentido recto y figurado), sino su conceptualización en aras de la precisión discursiva. Esta distinción permite, además, dar cuenta de que no se trata realmente de una oposición, como se entendía hasta ahora (sentido recto vs. sentido figurado), sino más bien de categorías tangenciales fruto de la naturalidad con la que a menudo se explotan las posibilidades expresivas del lenguaje; en términos cognitivistas de Lakoff $(2009,36)$, "metaphorical language works as a simple extension of non-metaphorical language". La relación entre el lenguaje figurado de primer grado y el de segundo es, pues, más de extensión que de oposición.

Aunque esta base terminológica resulta operativa para plantear la guía de estilo que se proyecta en este artículo, no ha de ol- 
vidarse que la complejidad semántica de la figuración es mucho mayor desde un punto de vista neurológico; no en vano, desde hace décadas hay un gran número de publicaciones en el ámbito de las ciencias cognitivas o la psicolingüística, cuyos postulados son más apropiados para abordar la figuración que, por ejemplo, la consabida -y hoy limitada- dicotomía entre langue y parole establecida por Saussure (2005, 20-21). Lo que aquí se propone es una tarea de cariz principalmente lexicográfico, para cuya ejecución la distinción entre una figuración verbal de primer grado y otra de segundo grado se antoja suficiente. No obstante, el estudio específico del lenguaje y de la figuración debe realizarse desde presupuestos neurocientíficos más elaborados. Sin ir más lejos, en la teoría neuronal se comprenden a su vez dos tipos de metáforas: primarias y conceptuales (Lakoff, 2009, 26-28), que aquí entrarían -muy grosso modo- como subtipos de la denominada figuración de segundo grado. En lo sucesivo se aludirá puntualmente a algunos de estos enfoques cognitivistas.

Sentadas estas bases, procede retomar la cuestión expuesta: ¿conviene emplear el lenguaje figurado 'de segundo grado' en el ámbito científico? Parece evidente que este tipo de figuración es legítima y enriquecedora para los usos más cotidianos de la lengua, pero ¿lo es también en disciplinas científicas, técnicas y doctrinales? Ya los filósofos analíticos del siglo XX, como Carnap, Frege o Russell, ambicionaban la creación de un lenguaje lógico, libre de indeterminaciones, que fuera plenamente exacto y objetivo en materia científica y filosófica (Mohler, 2017, 311). El proyecto, evidentemente, fracasó por utópico, pues el lenguaje no deja de ser una tecnología humana -un medio, una herramienta- $\mathrm{y}$, como tal, está sujeto a continuos cambios y reestructuraciones de tipo diacrónico. El ideal, sin embargo, no era del todo estéril: en palabras de Picardo (2018, 66), “el lenguaje científico intenta sistemáticamente ser más monosémico y eliminar la ambigüedad". Es precisamente en ese intento, en el afán mismo de objetividad, donde radica la verdadera razón de ser del lenguaje científico: dar cuenta de la realidad no de manera mimética ni 
absoluta (lo que supone una falacia descriptivista), sino, simplemente, del modo lo más neutral y aséptico posible. Se trata, por la naturaleza misma del lenguaje, de una praxis asintótica, y la figuración de segundo grado puede ser un recurso más para tal fin. En las líneas que siguen se hace una breve revisión de los postulados más relevantes al respecto.

No todos los académicos han querido ver en la figuración de segundo grado un recurso epistémico. Rafael Lapesa $(2008,37)$, por ejemplo, discriminó claramente un "sentido directo", que vinculó con el "lenguaje lógico" o "ideal de la exposición científica", de otro "sentido figurado", que asoció con el "lenguaje expresi$v o^{\prime \prime}$, más conveniente "para la expresión cargada de afectividad". Esta es, como se ha señalado, una dicotomía tan frecuente como irreal, pues no es posible separar el sentimiento del pensamiento (que se canaliza fundamentalmente - pero no solo- a través del lenguaje [Ongay, 2013]): lo que se piensa se siente y lo que se siente se piensa; como reza la máxima unamuniana, hay que sentir el pensamiento y pensar el sentimiento, porque no se puede pensar sin sentir ni sentir sin pensar. Lapesa parecía no concebir, en definitiva, que la figuración de segundo grado pudiera o debiera salir de lo literario, es decir, de lo artístico. De igual modo, no son pocas las publicaciones metacientíficas orientadas a la mejora en la redacción de textos de investigación en las que se aboga por segregar unilateralmente los considerados como recursos literarios de la claridad y precisión que se presupone al lenguaje científico. Así puede constatarse, por ejemplo, en el artículo de Alonso y Piñeiro $(2007,77)$, en el que describen la redacción científica como "muy distinta" de la literaria, en la que se utilizan recursos exclusivos "como la metáfora, el sentido figurado, el vocabulario florido y el misterio"; en Texidor, Reyes y Camejo $(2012,113)$ a propósito del ámbito de ciencias de la salud; o en García, Algas, Espinosa, Frómeta y Chávez $(2013,5)$, donde los riesgos de la aquí denominada figuración de segundo grado se ponen al nivel de la doble negación o el abuso de la impersonalidad: “Dentro de los elementos que pueden afectar la precisión de un texto cien- 
tífico se valoran el empleo de lenguaje figurado o metafórico, la doble negación y la utilización indiscriminada de lenguaje impersonal, entre otros". Como se puede observar, muchas de estas publicaciones destinadas a la mejora en la redacción de material científico llevan la firma de más de un autor por caso. También Lyotard (1979) habló, desde su difusa condición posmoderna, de la ciencia como discurso ("discours scientifique") y excluyó todo lenguaje no estrictamente denotativo del saber científico.

En general, estas posturas responden a lo que Eduardo Bustos $(2002,2-3)$ recoge como "ideas heredadas" de la tradición grecolatina y de autores como John Locke, que censuraba la figuración como un ejercicio por completo retórico en tanto en cuanto se utilizaba para seducir al público. Desde finales del siglo XX, no obstante, la propia ciencia se considera cada vez más una forma de retórica en la medida en que implica un consenso de la comunidad científica. Lejos de adolecer de posmodernidad, esta tendencia mantiene la preferencia por una argumentación concisa y eficiente (Duque, 1999, 16), al tiempo que abre la posibilidad de introducir recursos de figuración de segundo grado como la metáfora con fines expositivos y aclarativos. Así lo entienden Cuéllar y Villa (1997, 242), que ven en posturas como las enumeradas arriba un "lugar común" y defienden la posibilidad de servirse de tropos en la expresión del lenguaje científico sin perder "claridad y precisión", siempre y cuando se introduzcan "con inspiración e inteligencia". En la misma línea, Carmona $(2013,147)$ advierte que no debe extrañar el uso, "en ocasiones inadvertido", de tropos en el lenguaje científico, "válido si esas expresiones están bien definidas". Se concibe ahora, en particular, una 'metáfora científica' o 'epistémica', diferenciable de la literaria en que, como ha estudiado Héctor A. Palma $(2015,138)$, “tienen su propia historicidad y una suerte de biografía común: rápidamente mueren como metáforas y se literalizan. Lo que se inicia como una bisociación entre ámbitos ajenos, a partir del éxito y con el transcurrir temporal, acaba siendo una explicación literal en el ámbito adoptivo". El tránsito que sugiere el autor 
encaja perfectamente con lo que aquí se planteará en términos de intermultidisciplinariedad. Si se considera la epistemología como una teoría del conocimiento más general que la gnoseología, que sería estrictamente científica (Bueno, 2012), la denominación de metáfora gnoseológica sería también más restringente en comparación con la de metáfora epistémica.

La utilización de este tipo de figuración en la ciencia no es nueva. Ya en un libro de anatomía del siglo XVI como De humani corporis fabrica, del flamenco Andrés Vesalio, abundan las ilustraciones de disecciones humanas en poses de carácter alegórico, que bien funcionan como metáforas científicas visuales. En uno de sus ensayos de juventud, Borges (2017) escribió que "metaforizar es pensar, es reunir representaciones o ideas". Esto es especialmente común en vertientes académicas de la ciencia como la enseñanza o la divulgación científica, en las que afirmar, por ejemplo, que las nebulosas son vientres espaciales en los que nacen las estrellas amplía la inteligibilidad -especialmente fuera de la pura gnoseología- sin distorsionar la verdad, de la que la ciencia no puede dejar de dar cuenta. En palabras de Norberto de la Torre $(2003,98)$, "una metáfora nos dice algo nuevo sobre la realidad". En el ámbito de la enseñanza, como apunta también Palma $(2008,10)$ en su libro Metáforas y modelos científicos, los docentes explican la ciencia mediante metáforas al tiempo que los estudiantes estructuran su conocimiento científico a través de las mismas. En el terreno de la divulgación científica, Alcíbar (1999, 455) señala directamente la elusión del exceso de tecnicismos y el empleo del lenguaje figurado de segundo grado como "recursos literarios a disposición del divulgador científico". Si se tienen en cuenta casos a la inversa, como el mencionado en el epígrafe anterior de tecnicismos insertos en el Quijote o los esfuerzos de Andrés Bello en el siglo XIX por difundir la astronomía desde una retórica literaria (Ramírez y Leyton, 2017, 198), parece evidente que lo académico y lo literario se entrecruzan con relativa frecuencia. No en vano, en la última década incluso se han planteado actividades docentes de transformación retórica de textos 
científicos en literarios para fortalecer distintas competencias escritas del alumnado (Funes, 2013). Esto, huelga decir, no implica necesariamente pensar en la línea de Locke (1997, 31-32), que sostiene que ciencia y literatura son "ocupaciones hermanadas que proceden mano a mano en su persecución de los secretos del mundo". En puridad, la búsqueda de la verdad corresponde a la ciencia y a la filosofía, pero no a la literatura, cuyo rasgo intrínseco esencial es su condición de ficción. Precisamente si existe una ciencia de la literatura (la Teoría de la literatura) es porque la literatura pertenece al orden del arte y no al de la ciencia. Incluso cuando, de manera más o menos colateral, la literatura revela en ocasiones "secretos del mundo", su misión es distinta de la puramente científica.

Todas estas consideraciones no hacen sino evidenciar la disyuntiva entre utilizar o no la figuración de segundo grado en el ámbito científico. Conviene recurrir, en este punto, a uno de los sistemas más citados dentro de la lingüística cognitiva y la pragmática: la teoría de la relevancia, en la que Wilson y Sperber plantearon que la pertinencia de un enunciado viene determinada por el efecto cognitivo que produce en el receptor en un contexto determinado. En concreto, la noción de "optimal relevance" (Wilson y Sperber, 2004, 612) alude a la relación entre el esfuerzo invertido y la relevancia de los efectos cognitivos producidos. De acuerdo con este modelo, una expresión metafórica (figuración de segundo grado) puede resultar muy significativa a efectos científicos, siempre y cuando sea relevante en su contexto de enunciación y su inferencia resulte sencilla. En el caso de la ciencia, lo primero tiene que ver con cómo una expresión clarifica un determinado postulado o incluso amplia su sentido, mientras que lo segundo depende -al menos en cierta medida- del conocimiento previo sobre el tema que tengan quienes decodifican la metáfora. Lakoff $(2009,36)$, desde un enfoque cognitivista, afirma que "[1]anguage is meaningful when the ideas it expresses are meaningful. Conceptual metaphors are meaningful when they are grounded. They are grounded, first, 
by source domain embodiment, and second by the embodiment of the source and target domains of the primary metaphors being used". La metáfora -como, en general, el lenguaje figurado de segundo grado- es un recurso de amplio espectro, que activa distintos circuitos neuronales en el cerebro y que puede abarcar léxico de campos diferentes.

Se profundiza en estas cuestiones en los siguientes epígrafes. Baste por el momento recordar que, al considerar que todos los usos del lenguaje son figurados en sentido estricto, se ha propuesto diferenciar entre una figuración 'de primer grado' (el hasta ahora conocido como 'sentido recto') y una figuración 'de segundo grado' (el tradicional y vago 'sentido figurado'). Esta nueva distinción, como se ha explicado, es exclusivamente terminológica, pero utilizarla resulta más preciso en rigor lingüístico y permite sugerir que, más que una oposición entre uno y otro tipo de lenguaje (literal vs. figurado), lo que hay es más bien un salto entre ambos niveles de figuración. Para mayor especificación, en el marco de las disciplinas científico-técnicas se propone, además, particularizar esta distinción como figuración matriz y figuración radial. En paralelo a esta diferenciación, en el contexto científico y académico cabe concretar la nomenclatura general de lenguaje figurado como lenguaje interdisciplinar, ya que este último viene en realidad posibilitado por la figuración de segundo grado. En lo sucesivo se atiende a las implicaciones y matices esenciales de estas premisas y se valora la idoneidad de la figuración de segundo grado (figuración sin más, en el tradicional sentido laxo) en el ámbito científico.

\subsection{Interdisciplinariedad y multidisciplinariedad léxica}

El hecho de que las ciencias estén compartimentalizadas posibilita la interacción de unas con otras. Esta interacción, sin embargo, se ha conceptualizado de maneras ligeramente distintas. Así, en las últimas décadas se ha extendido el empleo de tres palabras derivadas con un significado parecido, pero no idéntico: multidisciplinar, transdisciplinar e interdisciplinar. Si se atiende 
a los prefijos que forman los vocablos, multi- refiere a una actividad relacionada con más de una disciplina, trans- implica ir más allá de las disciplinas e inter- remite a una relación de reciprocidad entre las disciplinas (Alvargonzález, 2011, 388). Sin embargo, la mera formación de las palabras no basta para dar cuenta de todas sus posibles implicaciones terminológicas. Choi y Pak $(2006,359)$ recomiendan utilizar el sustantivo multidisciplinariedad para referirse al conocimiento de diferentes disciplinas que se mantiene dentro de los límites de cada campo; transdisciplinariedad para la integración de las ciencias naturales, sociales y de la salud en un contexto de Humanidades (su clasificación difiere de la aquí propuesta); e interdisciplinariedad para unir disciplinas concretas de manera armónica, coordinada y coherente.

De entrada, podría considerarse que el término idóneo para la guía de léxico que aquí se propone es transdisciplinar, ya que sugiere la unificación de las ciencias en un único campo al que el vocabulario sería trasplantado. Esto, no obstante, tiene un fuerte componente idealista que no se corresponde con la pluralidad de los campos científicos: la unión de estos últimos resulta quimérica porque no es posible -al menos hasta la fecha- unificar los principios de una ciencia como la Física con los de otra como la Biología. Cada campo consta de teoremas y paradigmas propios e inalienables, de manera que en un campo como la Geometría no procede pensar en un rasgo como el color, atinente a la Óptica (Alvargónzalez, 2010, 5). Del mismo modo, no cabe plantear que el lenguaje científico de un campo pueda ser operativo en otro con las mismas implicaciones conceptuales (aunque sí, desde luego, con otras). Como también afirma Muñoz Rengel (2020, 203), "[1]a idea de la ciencia como un todo unívoco, en el que todas las especialidades y sus teorías son compatibles, $[. .$.$] no es más que otra invención de la$ sociedad moderna y de sus comunidades científicas". Por todo ello, catalogar de lenguaje transdisciplinar el hecho de emplear términos de una disciplina en otra conduciría a una falsa idea de monismo y homogeneidad. 
En su lugar, procede trabajar en términos de lenguaje multidisciplinar $\mathrm{y}$, sobre todo, interdisciplinar. Como argumenta Alvargonzález $(2010,4)$, “la interdisciplinariedad supone la autonomía de cada una de las disciplinas, y no nos saca de ese marco clásico de fragmentación del conocimiento". En el caso particular del lenguaje, la noción de interdisciplinar posibilita la utilización de un término de una disciplina en otra sin que su sentido original quede unificado como un único significado. En otras palabras, el lenguaje interdisciplinar permite generar nuevos usos de palabras en disciplinas distintas de la matriz, de manera que exista más de un uso operativo del término en función del campo en el que se utiliza. Estas disciplinas pueden ser científicas (Biología, Química, Psicología) o no (Derecho, Filosofía, ingenierías). Así, por ejemplo, la palabra asíntota (que refiere en Geometría a una línea recta que se acerca infinitamente a una curva sin tocarla jamás) puede emplearse en parcelas de las ciencias humanas tales como la crítica textual o el análisis lingüístico con el sentido de aproximativo (como se ha utilizado en el punto 3.1. de este artículo). No en vano, se trata de un uso ya registrado en algunos trabajos académicos de campos como la semiótica; en Análisis de la significación del videojuego, por ejemplo, Pérez Latorre $(2010,63)$ escribe:

Efectivamente, la sofisticación analítica de la semiótica textual parte de la base de que una aproximación asintótica a la descripción completa de la significación de un texto es posible. "Aproximación asintótica" implica conciencia de la imposibilidad de una descripción completa de la significación de un texto, pero al mismo tiempo compromiso analítico en pro de un acercamiento honesto a dicho objetivo.

Huelga decir que el uso interdisciplinar del vocablo no anula la figuración de primer grado en su campo original, la Geometría. Tanto en la disciplina primigenia como en la nueva, el término mantiene su autonomía y, por consiguiente, tiene significados ligeramente distintos, que pueden recogerse como acepciones diferentes en un diccionario lexicográfico (sabiendo que en este se 
tiende a incluir lo que dicen los hablantes y, por lo tanto, a dejar fuera muchos términos específicos del ámbito de las ciencias). A efectos conceptuales puede hablarse de figuración matriz, esto es, la acepción común u original (ej. la asíntota de la gráfica de una función), y de figuración radial, es decir, aquella en la que el término se utiliza fuera de su especialidad y en sentido extendido (ej. la felicidad es una asíntota). Esta distinción, adelantada en el epígrafe anterior, no es necesariamente incompatible con la ya propuesta de figuración de primer y segundo grado, que podría utilizarse en un sentido más amplio y aplicarse al lenguaje de uso común en general, reservando esta para el científico-técnico. Más allá de la nomenclatura, la concepción de un lenguaje interdisciplinar permite revocar muchas de estas laxitudes expresivas y sus consiguientes teorías correctivas. Caben, no obstante, dos circunstancias que merecen una explicación más pormenorizada.

La primera de ellas tiene que ver con la idea de multidisciplinariedad. Si bien, tal y como se ha ejemplificado, la noción de interdisciplinariedad legitima que una misma palabra tenga usos figurados distintos en campos diferentes, hay términos que, por la realidad que designan, no varían realmente de uso aun en campos dispares. Un caso ilustrativo es el de fractal, un concepto matemático utilizado para aludir a una estructura iterativa cuya apariencia y distribución estadística son la misma con independencia de la escala en que se observe. La peculiaridad del vocablo se encuentra en que, al referir a un tipo de patrón geométrico que puede darse también fuera del ámbito de las ciencias formales, no es posible adscribirlo a un único campo en el que tenga un sentido original a partir del cual surjan nuevos usos. Sin ir más lejos, Drożdż, Oświęcimka, Kulig, Kwapień, Bazarnik, Grabska-Gradzińska, Rybicki y Stanuszek (2016) han observado que muchas obras literarias -con frecuencia las que utilizan la técnica del fluir de conciencia (stream of consciousness)- están regidas por la dinámica de los fractales; algunas, como The Waves (1931), de Virginia Woolf o Rayuela (1963), de Julio Cortázar incluso presentan estructuras multifractales, resultantes del entretejimien- 
to proporcional de otros fractales (Martínez, 2016). Del mismo modo, en la arquitectura de templos como los nagara indios subyacen conceptos fractales que corroboran su presencia en el campo de la Historia del Arte (Ostwald y Vaughan, 2016, 28-29). En consecuencia, no parece pertinente hablar de 'usos distintos del concepto de fractal' aun si se trata de disciplinas diferentes; en todo caso, cabría matizar que el término mantiene su significado en uno y otro campo porque designa una realidad similar, categorizable como una en ambas disciplinas. Es en este punto donde procede considerar la noción de multidisciplinariedad, que, como se indicó, admite la existencia de un conocimiento relativo a más de una disciplina sin abandonar los límites de cada una de ellas. De esta manera, un concepto como fractal es multidisciplinar en tanto en cuanto concurre en varios campos sin mutar de sentido.

¿Debe, pues, insertarse también la multidisciplinariedad en el marco de léxico científico aquí propuesto? A tenor de lo argumentado, su inclusión es ciertamente factible y pertinente, si bien se plantean algunos problemas a efectos nominales. Caben dos opciones: 1) soldar los dos prefijos en un solo término, el ya utilizado intermultidisciplinar, que da cuenta de las dos vertientes; o 2) incluir los casos de léxico multidisciplinar en el mismo paraguas de la interdisciplinariedad, aun cuando suponga incurrir en una leve homogeneización. En este segundo escenario, habría de explicitarse como caución (bien a efectos generales para toda la guía, bien en cada uno de los casos particulares en los que proceda dentro de la misma) que estos casos de multidisciplinariedad se tratan como un tipo de interdisciplinariedad en la que el significado no varía, sino que simplemente se aplica a una disciplina diferente. Así, coexistirían dos variantes dentro de un mismo marco de interdisciplinariedad: aquellas que adquieren otro sentido en la nueva disciplina, como ocurre con asintota; y aquellas otras que comparten un sentido similar en disciplinas distintas, como sucede con fractal. De cara a la guía proyectada, aquí se presta especial atención a la noción de interdisciplinarie- 
dad por el mayor número de palabras que cubre, pero sería igualmente importante atender a los casos de multidisciplinariedad y, acaso, dar cuenta de ellos desde el título mismo: Guía de léxico científico intermultidisciplinar para las ciencias humanas e históricas, como posibilidad.

La segunda circunstancia tiene que ver con el alcance lingüístico del hipotético catálogo. Al tratarse de un inventario de léxico científico y técnico (son, recuérdese, ámbitos distintos, si bien ambos se encuentran en el cuadro de lo disciplinar), hay palabras que quedan fuera del registro, al menos en calidad de posibles entradas del mismo. Las preposiciones, por ejemplo, han sido tradicionalmente $-\mathrm{y}$ en general- consideradas palabras con significado gramatical pero no léxico (Cuartero, 2002, 75). Aunque cabe entender que participan del sentido de palabras que sí tienen significado léxico (no es lo mismo diagnosticar a, diagnosticar por o diagnosticar para), las preposiciones no podrían contemplarse en este caso más que como elementos periféricos de la unidad léxica inventariada. Por otro lado, hay palabras cuya especificidad científica o técnica puede resultar incierta. ¿Pertenecen todas las palabras con significado léxico a un campo científico-técnico concreto o pueden, al menos, circunscribirse a alguno en particular? La idea de campo semántico, enraizada en la lingüística, no parece la más indicada aquí porque no contempla las diferentes disciplinas de manera directa, tal y como se propuso en el epígrafe anterior. Existen, además, palabras que, aun pudiendo adscribirse a un campo específico, se encuentran tan extendidas en el uso común de la lengua que parecen haber perdido cierto carácter científico-técnico. Si se compara, por ejemplo, un término como vacuna con otro como hematemesis se constata, mediante la mera percepción, que el primero -aun perteneciendo al campo de la medicina desde su origen- es mucho más conocido y utilizado por los hablantes legos en las ciencias médicas que el segundo; sin ir más lejos, vacuna ha adquirido usos figurados de segundo grado con el tiempo y puede aprovecharse en el discurso de campos como el de las ciencias históricas: en la oración 
la reforma laboral sirvió de vacuna para la difícil situación social, el uso de la palabra vacuna aporta matices concretos con respecto a otras posibles formas de denotar una realidad histórica precedente. Otras palabras pueden tener usos concretos en determinados campos que el grueso de usuarios de la lengua desconoce; la palabra especificidad, por ejemplo, se utiliza en Epidemiología (esto es, el tratado de las epidemias) para indicar la probabilidad que un sujeto sano tiene de obtener un resultado negativo en la prueba. El conocimiento de esta terminología puede extenderse entre la población en un momento dado (véase el caso de una pandemia como la del COVID-19) e incluso situarse en un nivel de uso cercano al de vocablos más frecuentes, como parece ocurrir actualmente con pares como alopecia-calvicie.

Todo esto tiene implicaciones que deben contemplarse para la confección de un catálogo o inventario como el que aquí se propone. A efectos de ejecución, la decisión principal que ha de tomarse tiene que ver con qué palabras registrar exactamente. La gran mayoría de palabras con significado léxico es incluible en las categorías de alguna disciplina, desde las científicas (en zoología, por citar una, la forma más extendida rinoceronte frente a la más específica rinocerótido) hasta las técnicas (engranaje), pasando por las doctrinales filosóficas (ser) y jurídicas (litigar). Puesto que aquí se busca trabajar con terminología compartimentalizada, el criterio más apropiado parece directamente el de la potencialidad figurativa, es decir, la capacidad de los hablantes mediante las palabras para generar nuevos usos en las ciencias humanas. Un catálogo de lenguaje interdisciplinar como el planteado habría de priorizar -cuando no limitarse a- aquellos términos en los que previamente se detecte una posibilidad de aprovechamiento en clave de usos figurados radiales. De este modo, sería poco provechoso -al menos a priori-incorporar al inventario un concepto muy concreto como faradio, que refiere a una unidad de capacidad eléctrica difícilmente extrapolable fuera de la Física. Convendría, asimismo, evitar aquellos casos en los que el tecnicismo es posterior a la palabra en sí (es decir, en los que la 
especialización del término se da a partir de un vocablo preexistente) o en los que existe un uso más común que el propio tecnicismo, como sucede con homogéneo y heterogéneo (que se utilizan también, de forma específica, en Química para designar tipos de sistemas). Por el contrario, sería esencial optimizar la inclusión de todos aquellos términos con usos figurados más allá de su disciplina; véase, por ejemplo, excipiente, un concepto farmacológico que designa una sustancia añadida a los medicamentos para dotarlos de nuevas propiedades que faciliten su manejo.

Además de en el lenguaje cotidiano, la figuración de segundo grado se da, pues, de forma recurrente en las disciplinas de especialidad, sin que ello suponga necesariamente una merma en su estatuto de verdad. Para propiciar el intercambio de terminología entre campos se aboga, en suma, por la idea de interdisciplinariedad léxica, a la que se suma la de multidisciplinariedad para aquellos casos concretos en los que el significado de la palabra es el mismo aun empleándose en campos distintos. Si se optara por no utilizar el término único intermultidisciplinar, sería necesario apostillar la presencia de léxico multidisciplinar relevante. Por otro lado, cabe aclarar que el hecho de que el resultado final del inventario tenga la forma de categorías léxicas compartimentalizadas no implica que, en otras situaciones, no se puedan realizar también distinciones más gruesas -menos rígidas- a fin de facilitar la localización de términos de interés, entre otros motivos.

\section{Hacia una guía de léxico interdisciplinar para las ciencias humanas e históricas}

En las ciencias humanas e históricas se trabaja principalmente -aunque no solo- con signos referenciales del sistema lingüístico, lo que implica algunas diferencias con respecto a aquellas disciplinas en las que se opera más con signos de carácter autorreferencial. En estos últimos casos, como argumenta Eurrutia $(2003,368)$, la figuración radial o de segundo grado neutraliza "la objetividad y esterilidad alfanumérica" del término científico y lo reemplaza "por otro más evocador, expresivo y familiar al 
lector que hace posible la reformulación de teorías, la descripción de fenómenos, procesos, mecanismos". Se trata de una "doble finalidad, estética y funcional", en la que no se oblitera el concepto por mero arbitrio (sin conceptos no hay ciencia), sino que se propicia la construcción de nuevos teoremas desde la paráfrasis lingüística. En las ciencias humanas, sin embargo, la incidencia de la figuración radial tiende a ser más estética que funcional por la preponderancia que tiene la palabra en la constitución de los campos, lo que quizás explica la ausencia hasta la fecha de un inventario de léxico interdisciplinar como el aquí propuesto. Jerzy Pelc $(1997,269)$ aporta información valiosa para esclarecer este hecho y entender mejor el desprestigio formal que a veces sufren las ciencias humanas e históricas:

Para desentrañar los teoremas y argumentos de las ciencias formales, es necesario estar familiarizado, entre otras cosas, con los símbolos utilizados. Las disciplinas humanísticas, por otra parte, emplean lenguajes naturales, convenientemente adaptados a las necesidades de las culturas a las que pertenecen. Aun cuando utilicen ocasionalmente palabras o términos especiales cuyos significados se aparten de sus sentidos cotidianos, nada impide que se puedan traducir a un lenguaje que los destinatarios, con las modificaciones adecuadas, sean capaces de entender. Podemos, ciertamente, considerar como destinatarios de esta especie a todos los humanistas representantes de otros campos, disciplinas o especialidades titulados en escuelas de educación superior. De hecho, incluso estudiantes de humanidades o personas que hayan completado el bachillerato pasablemente pueden entender las palabras y escritos de un humanista, pero sólo si este último piensa, habla y escribe de manera lúcida, clara y precisa - en resumidas cuentas, si se expresa sin vaguedad.

En consonancia con esto, Eurrutia $(2003,368)$ aporta asimismo una valiosa doble distinción entre tropos libres y tropos léxicos, por un lado; y entre tropos innecesarios o de lujo y tropos necesarios, 
por otro. Mientras que los primeros atañen más a la estética y a la riqueza discursiva, los segundos son aquellos ya lexicalizados y establecidos -a menudo a partir de los anteriores- en el lenguaje de las distintas disciplinas. No cabe ocultar, por lo tanto, que el uso de un lenguaje interdisciplinar en las ciencias humanas tiene a menudo un efecto más decorativo, de enriquecimiento formal del discurso, que en las ciencias formales y/o naturales. Esto, en cualquier caso, no implica necesariamente una pérdida de exactitud o rigor, pues el designar una realidad con un término de otro campo puede resultar tanto o más preciso y permite embellecer la exposición (escrita u oral). Por ejemplo, si en campos como la Historia o la Sociología se quiere expresar que Europa es una unión de diferentes países con funcionamientos internos dispares (una totalidad distributiva, en términos de Materialismo Filosófico [Bueno, 2010]), se puede: 1) realizar una paráfrasis con una expresión más o menos genérica: ej. la Unión Europea está integrada por más de veinte estados con distinta estructura política; o 2) recurrir a la figuración radial de un concepto interdisciplinar oportuno, como pueda ser biocenosis (Biología): ej. la Unión Europea es una biocenosis de más de veinte estados. En este segundo caso, el uso figurado radial de biocenosis (un grupo de organismos de especies variadas, en sentido figurado matriz) da cuenta per se del sentido deseado, al tiempo que le confiere un cierto estatuto estético a modo de elegancia formal.

Evidentemente, el abuso de este tipo de figuración de segundo grado es desaconsejable. La ya referida teoría de la relevancia (Wilson y Sperber, 2004) es elocuente al respecto: no se trata de henchir el discurso de las ciencias humanas e históricas con términos de otros campos hasta el punto de literaturizarlo y hacerlo ininteligible, sino de insertarlos con pertinencia para enriquecer la expresión sin mermar la condición de verdad. Un exceso de estos recursos podría devenir en ambigüedad, a todas luces refractaria al discurso científico. Por citar un ejemplo cualquiera de esta situación, Jorge Urrutia (1976, 91-92) llegó a argüir, en materia de Teoría de la literatura, que "uno de los defectos de 
la crítica estilística es su abuso del lenguaje metafórico. [...] Los estilólogos no se refieren a temas divinos y, por tanto, deberían ser menos dados a la metáfora". La práctica lingüística interdisciplinar que aquí se propone tiene mucho de guía y poco o nada de dogma; de ahí que se prefiera evitar el uso de palabras como diccionario o incluso manual, pues la motivación no es en absoluto doctrinal. Se busca proyectar, desde la teoría, la creación de una guía de estilo para un aspecto muy concreto del lenguaje científico, dada la ausencia de un inventario que recoja, a modo de catálogo, un número amplio de términos aprovechables de manera interdisciplinar. Así, sería conveniente que las entradas con las palabras registradas formaran parte de una guía como tal, en la que se establecieran previamente y con claridad los fundamentos teóricos y las principales 'recomendaciones' -más que pautas- de uso. La Guía de léxico inter(multi)disciplinar para las ciencias humanas e históricas -como posible título- que aquí se proyecta podría funcionar como un material de consulta de cara al enriquecimiento del discurso (escrito y oral) en las ciencias humanas e históricas. En la última década se han publicado, entre otros, el Diccionario de expresiones y locuciones del español (Martínez y Myre, 2009), el ya citado Diccionario bilingüe de metáforas y metonimias científico-técnicas (Cuadrado, Argüelles, Durán, Gómez, Molina, Pierce, Robisco, Roldán y Úbeda, 2016) y el Libro de estilo de la lengua española según la norma panhispánica (Real Academia Española y Asociación de Academias de la Lengua Española, 2018). Las fechas de publicación de estas tres obras no son sino reflejo de un momento de fertilidad para la producción de este tipo de materiales.

En este punto, conviene aclarar que la interdisciplinariedad de unas ciencias con otras que se plantea atañe única y exclusivamente al léxico y a la terminología lingüística, no a los teoremas ni construcciones propias de cada campo (con la salvedad, ya comentada, de conceptos potencialmente multidisciplinares como fractal). Que después se den intersecciones como la bioquímica o la geofísica o que las ciencias formales, en cuanto que autorrefe- 
rentes, tengan una contrapartida en otros campos son cuestiones de otra índole que no afectan a la interdisciplinariedad léxica. La novedad de esta posible guía de léxico interdisciplinar con respecto al mencionado Diccionario bilingüe de metáforas y metonimias científico-técnicas radica sobre todo en que este último comprende exclusivamente la figuración de segundo grado en expresiones lexicalizadas, ya establecidas, dentro de cada campo. La guía aquí propuesta habría de beber de ello para configurarse con base en sus propios objetivos. De cara a su hipotética confección, sería necesario realizar un rastreo de terminología científica y técnica, a la que podría sumarse la de sistemas doctrinales fecundos en léxico, como el Derecho. De esta selección podría derivar una marcación diatécnica, parecida tal vez a la elaborada por Pilar Díez de Revenga $(2003,271)$ a propósito del "trasvase continuo entre el léxico de la lengua común y el de las lenguas de especialidad" (el registro, en realidad, pues la lengua es la misma). La marcación diatécnica de la figuración matriz debería estar abierta a intersecciones como las citadas. Hay una gran cantidad de términos que pueden resultar operativos en más de una disciplina y que, por lo tanto, no tienen una marcación única; es el caso, por ejemplo, del adjetivo maleable, que se utiliza en ciencias como la Química, pero también en distintas ingenierías, como la mecánica. De haberlas, podrían indicarse también las distintas clases de palabra existentes para un mismo término, como el sustantivo maleabilidad para el anterior.

Otra cuestión, quizás de menor importancia si se trata sobre todo de ofrecer un glosario para uso del académico pero que también habría que tener en cuenta, es el momento de tecnificación del término, ya que hay conceptos cuyo uso científico es posterior a la palabra en sí. Esta información no es fácil de determinar en muchos casos, en especial porque muchas disciplinas ni siquiera existían como tales cuando las palabras que hoy se integran en ellas ya se utilizaban. En una de sus conferencias sobre el discurso de las ciencias humanas, Derrida (1966) utilizó el término anaclástica, que hoy ha quedado casi reservado al ámbito de la Física y la Óptica pero que, como él mismo explica, tuvo un 
uso anterior más frecuente: "la science des mythes est une anaclastique, en prenant ce vieux terme au sens large autorisé par l'étymologie, et qui admet dans sa définition létude des rayons réfléchis avec celle des rayons rompus". En un caso así, el empleo no es realmente interdisciplinar, sino que simplemente se recupera un uso que la palabra ya tenía. Por otro lado, es innegable que hay términos mucho más expandidos que otros: perpendicular (Geometría), diagnosticar o nutrición (Medicina) son tres ejemplos de palabras que, aun siendo de especialidad, han adquirido usos figurados de segundo grado muy habituales fuera de sus campos: hechos perpendiculares como 'sucesos complementarios'; un diagnóstico de la situación social, en el sentido de análisis; o nutrición intelectual para indicar beneficio mutuo a efectos de conocimiento.

A la marcación diatécnica podría acompañar una referencia a aquellos campos de las ciencias humanas donde el uso figurado radial del término resulta más fructuoso. Sin embargo, hacerlo supondría probablemente una delimitación excesiva de las posibilidades de figuración radial de los términos inventariados, por lo que resultaría seguramente más conveniente incluir tan solo el campo -o campos- de origen a modo de orientación. Como última indicación de peso en vistas de una hipotética elaboración, ha de remarcarse la importancia del trabajo interdisciplinar: este proyecto sería difícilmente abordable en solitario. Aunque quizás no imposible, como demostró Moliner con su Diccionario de uso del español, la naturaleza marcadamente interdisciplinar de la propuesta y el grado de especialización de los campos científicos, técnicos y doctrinales actuales hacen que resulte primordial trabajar de manera coordinada. Una guía de carácter interdisciplinar ha de ser el resultado de un esfuerzo entre disciplinas.

Un último aspecto que cabría considerar, pero que excede las posibilidades del presente trabajo, tiene que ver con la traducción: ¿Qué ocurre en otras lenguas? ¿Sería esta misma interdisciplinariedad terminológica aplicable en otros idiomas? El problema para traducir los usos figurados de segundo grado en el lenguaje científico-técnico no es nuevo, y, aunque se han conce- 
bido diferentes métodos para ello, la disparidad de opiniones en torno a su traducibilidad sigue siendo grande (Elizondo, 2002). De acuerdo con el célebre principio de indeterminacy of translation del filósofo analítico Quine (2013), la traducción plena no es posible en la medida en que el lenguaje va ligado a las culturas que lo amparan y, si se traduce, el trasfondo cultural cambia de modo irremediable. Este principio queda comprometido en el caso de la ciencia, cuya relación con la cultura no va más allá del entorno social y político que posibilita su construcción. Aunque pueda, si se quiere, existir una cultura de la ciencia, esta última no es cultura; la ley de gravitación universal, por ejemplo, no es inglesa por el hecho de que la formulara un físico inglés, sino que responde a principios científicos ajenos a la cultura en sí. De esto podría deducirse que el lenguaje científico-técnico está, en realidad, exento de la indeterminación planteada por Quine, que afecta a la cultura pero no a la ciencia. Sin ir más lejos, el Glosario bilingüe de matemáticas (2011) o el Diccionario bilingüe de metáforas y metonimias científico-técnicas están, como sus propios títulos indican, confeccionados en español y en inglés. En cualquier caso, cuando hay un efecto de figuración radial como el que aquí se propone explotar, la traducción sigue siendo un ejercicio factible en lo práctico (es decir, a todas luces ejecutable) pero comprometida en lo teórico y estrictamente científico. La traducción automática, por ejemplo, es un recurso utilizado con frecuencia en textos científicos porque se parte de la idea -muy probablemente errónea, como se ha expuesto- de que en estos no hay figuración de segundo grado (Amores, Chacón, Martín, Montero, Román y Salas, 1997, 9). Norberto de la Torre (2003, 98), en cambio, afirma directamente que "las verdaderas metáforas no se pueden traducir". En el presente caso se proyecta, pues, la realización de una obra monolingüe, habiéndose de sopesar después, con más planificación, la posibilidad de la traducción a otros idiomas.

Sin más afán que el ilustrativo, se ofrece a continuación un muestrario de términos potencialmente incluibles en el eventual catálogo. Se han considerado hasta ocho disciplinas distintas. 
Para cada una de ellas se aporta un ejemplo, de entre los conceptos seleccionados, de un posible uso figurado radial en un campo concreto de las ciencias humanas o históricas (indicado justo al final entre paréntesis). Por tratarse de un simple prototipo, se han obviado las concurrencias de un mismo término en más de un campo.

- Matemáticas: fractal, factor común, capicúa. Ejemplo: La sustantivación es un factor común en todo el texto (Lingüística).

- Geometría: oblicuo, inflexión, tangente, poliédrico, perpendicular, intersección, parábola, mediatriz, bisectriz, asíntota. Ejemplo: Las guerras civiles son un elemento bisector para la humanidad (Antropología).

- Medicina: radiografía, diseccionar, biopsia, estenosis, caquexia, divertículo, esterilizar, anestesiar, inocular, triaca, sintoma, diagnosticar, hiperestesia, ortopédico, analgésico, lavativa, auscultar, anemia, emplasto, nutrición, vacunar, excipiente. Ejemplo: La traducción del fragmento resulta ortopédica (Traductología).

- Biología: embrionario, recesivo, fagocitar, diploide, simbiosis, hibridación, luminiscencia, ínfero. Ejemplo: La Unión Soviética fagocitó diversos países en su territorio (Geografía política).

- Física: gravitar, inercia, ósmosis, atomizar, entropía, espectro. Ejemplo: La colonización produce un efecto de ósmosis intercultural (Sociología).

- Química: oxidación, matraz, catalizador, solidificación. Ejemplo: El desamor puede ser catalizador de la depresión (Psicología).

- Derecho: abrogar, derogación, litigar, in articulo/periculo mortis, reconvenir, sobreseer, sua sponte, subrogar. Ejemplo: La figura del autor es inderogable (Teoría de la literatura).

- Ingeniería: cogeneración, resiliencia, dúctil, engranaje, golpe de ariete, soldadura, resorte, bidimensionalidad, retroalimentación, calicata, maleable. Ejemplo: Su negativa supuso un golpe de ariete en el desarrollo del conflicto (Historia). 
La Medicina y el Derecho, en particular, son dos de las disciplinas más fértiles para la búsqueda de posibles nuevos usos figurados de segundo grado. Investigaciones como la de Gilberto Castro (2014) corroboran la enorme mina que el léxico de la Medicina supone para tal propósito. De cara a la elaboración de la guía convendría examinar diccionarios e inventarios terminológicos de especialidad, a fin de extraer aquellos con un mayor potencial figurativo radial.

\section{Conclusiones}

En esta investigación se ha partido de la premisa de que una guía de estilo basada en el uso de léxico interdisciplinar en las ciencias humanas e históricas es factible. Con el fin de establecer algunos de los pilares teóricos sobre los que esta propuesta habría de cimentarse, se han considerado diferentes aspectos de índole filosófica y lingüística repartidos en dos bloques: «Las ciencias humanas e históricas» $\mathrm{y}$ «Figuración y lenguaje interdisciplinar».

En el primero se ha abogado por la concepción de las ciencias humanas e históricas como campos con presencia del sujeto gnoseológico (lo que no invalida sus respectivas condiciones de ciencia). Se ha ofrecido, asimismo, una clasificación de las ciencias enraizada en los presupuestos del cierre categorial de Gustavo Bueno y en las posteriores divisiones realizadas recientemente por David Alvargonzález. Se ha argumentado que 'lo científico' es una parte constitutiva esencial de 'lo académico', de manera que el uso del lenguaje en este último dominio puede ser algo más cercano al de la divulgación, pero sin perder nunca de vista los presupuestos estrictamente científicos.

En el segundo bloque se ha examinado el hecho -muy pocas veces considerado- de que todos los usos del lenguaje son, en realidad, figurados. Así, a fin de paliar la vaguedad teórica en la que a menudo se incurre al hablar de figuración, se ha propuesto distinguir, a efectos puramente terminológicos, entre usos figurados de primer grado (correspondientes al conocido como sentido 
recto) y usos figurados de segundo grado (correlativos al tradicional e indeterminado sentido figurado). Se ha expuesto que la relación entre uno y otro tipo es más de extensión que de oposición. En paralelo, se ha planteado una segunda diferenciación entre figuración matriz y figuración radial o extendida, similar a la anterior pero aplicable sobre todo al lenguaje de especialidad científico-técnica en particular. Hecha esta distinción, se ha abogado por la noción de lenguaje interdisciplinar para el empleo de terminología de unos campos en otros, al tiempo que se ha señalado la presencia de términos multidisciplinares de los que también cabría dar cuenta en la guía, ya sea a través de un único vocablo que forme parte del título de la obra (intermultidisciplinar) o mediante una apostilla aclaratoria como la sugerida en este trabajo. Se ha concluido que, en general, el uso de la figuración radial en el ámbito científico y académico es pertinente e incluso positivo si se realiza con pertinencia y en su justa medida.

A partir de estos presupuestos, se han esbozado algunas de las características principales que una guía de estilo -más que un diccionario- de léxico interdisciplinar debería cumplir para su uso en los campos concretos de las ciencias humanas e históricas. En estos, el empleo de la figuración de segundo grado tiene una función eminentemente estética, si bien en ocasiones puede ayudar a detallar y precisar los matices gnoseológicos considerados en cada caso. Enfatizando la necesidad de colaboraciones interdisciplinares para la elaboración del repertorio, se ha resaltado la importancia de realizar una marcación diatécnica de los términos inventariados, sin que esto sea óbice para realizar distinciones deliberadamente imprecisas en otros casos de cara a facilitar la búsqueda y localización de léxico aprovechable de manera interdisciplinar. Se han sopesado, asimismo, algunos posibles riesgos de acometer una traducción a otra lengua de la hipotética guía, si bien haría falta un análisis más pormenorizado de esta opción.

No son pocas las limitaciones del presente trabajo, cuyo valor -si alguno- puede estar en la revisión teórica general, en algunas 
de las aportaciones concretas realizadas de cara a la confección del catálogo de léxico o en la propuesta misma de este último. Puesto que no tienen una especial incidencia en el correcto diseño de la guía que se ha proyectado, la tradición cognitivista o la teoría de la relevancia se han considerado solo de manera puntual; no obstante, no puede dejar de decirse que el estudio de la figuración, como del lenguaje en general, precisa de la neurociencia en mucha mayor medida de la que aquí, por falta de necesidad, se ha utilizado. Lejos de pretender agotar un tema harto extenso, se ha intentado participar del estudio del lenguaje científico en el ámbito académico mediante reflexiones que, más que cerrar, abran nuevas posibilidades en términos de interdisciplinariedad léxica. Demarcados los límites que separan unos campos de conocimiento de otros, un enriquecimiento entre el léxico de los mismos es sin duda posible. El tiempo y la voluntad de quien corresponda dirán si el proyecto de guía planteado se consuma en forma de edición (física y/o digital) o si, por el contrario, queda en mera abstracción.

\section{Referencias bibliográficas}

Alcíbar, Miguel (1999) “De agujeros, espirales inmortales y guerreros: (una aproximación al estudio de la metáfora en ciencia y divulgación científica)", Cauce: Revista de filología y su didáctica, 22-23, 453-468, recuperado de https://cvc.cervantes.es/literatura/cauce/pdf/cauce22-23/cauce22-23_24.pdf (última consulta: 03/04/21).

Alonso, Miguel \& Piñeiro, Nereida (2007) “¿Cómo escribir un artículo científico?", Alcmeon, Revista Argentina de Clínica Neuropsiquiátrica, 14(2), 76-81, recuperado de http://alcmeon.com. ar/14/54/11_Nereyda.pdf (última consulta: 03/04/21).

Alvargonzález, David (2010) “La transdisciplinariedad como mito milenarista", Encuentros multidisciplinares, 34, 1-9, recuperado de http://www.encuentros-multidisciplinares.org/Revistan\%BA34/David\%20Alvargonz\%E1lez\%20Rodr\%EDguez.pdf (última consulta: 03/04/21). 
Alvargonzález, David (2011) "Multidisciplinarity, Interdisciplinarity, Transdisciplinarity, and the Sciences", International Studies in the Philosophy of Science, 25(4), 387-403.

Alvargonzález, David (2019) "La clasificación de las ciencias desde la filosofía del cierre categorial", Revista de Humanidades, 37, 99-126, DOI: https://doi.org/10.5944/rdh.37.2019.21202 (última consulta: 03/04/21).

Alvargonzález, David (2020) “Rasgos genéricos y específicos de las ciencias", Eidos, 32, 18-39.

Amores, Gabriel; Chacón, Rubén; Martín, Marina; Montero, José María; Román, Patricia; Salas, Pablo (1997) “Traducción automática de términos científico-técnicos unidos por guion de español a inglés", Philologia Hispalensis, 11(2), 9-19, recuperado de https://idus.us.es/bitstream/handle/11441/47554/art_1\%20 (1).pdf;jsessionid=ACE32A54DD73F93F7B97395301C6C8DD?sequence $=1$ (última consulta: 03/04/21).

Borges, Jorge Luis (2017) “El culteranismo”, El idioma de los argentinos (1928), recuperado de https://borgestodoelanio.blogspot.com/2017/07/jorge-luis-borges-el-culteranimso.html (última consulta: 03/04/21).

Bueno, Gustavo (1978) “En torno al concepto de 'ciencias humanas'. La distinción entre metodologías $\alpha$-operatorias y ß-operatorias", El Basilisco, 2, 12-46.

Bueno, Gustavo (1992) Teoría del cierre categorial. Introducción general. Siete enfoques en el estudio de la Ciencia (Parte I, sección 1), Oviedo, Pentalfa.

Bueno, Gustavo (2004) “Propuesta de clasificación de las disciplinas filosóficas", El Catoblepas, revista crítica del presente, 28, recuperado de http://nodulo.org/ec/2004/n028p02.htm (última consulta: 03/04/21).

Bueno, Gustavo (2010) “Todos atributivos y todos distributivos", Youtube, recuperado de https://www.youtube.com/watch?time_continue $=1 \& v=u$ _O5rqjeKHM\&feature $=e m b$ logo (última consulta: 03/04/21). 
Bueno, Gustavo (2012) “Diferencias entre gnoseología y epistemología", Teselas, 104, recuperado de http:/fgbueno.es/ $\mathrm{med} /$ tes/ (última consulta: 03/04/21).

Bustos, Eduardo (2002) “La metáfora y la filosofía contemporánea del lenguaje”, A Parte Rei. Revista de Filosofía, 19, 1-11, recuperado de http://serbal.pntic.mec.es/ cmunoz11/bustos3. pdf (última consulta: 03/04/21).

Carmona, Juan Carlos (2013) “Discurso y artículo científico. Una aproximación retórica”, Ra Ximhai, 9(1), 117-152, recuperado de http://uaim.edu.mx/webraximhai/Ej-26articulosPDF/07-JuanCarlosCarmonaSandoval.pdf (última consulta: 03/04/21).

Carnap, Rudolf (1953) "Formal and factual science", Readings in the Philosophy of Science, 123-128.

Casares, Almudena; Jiménez, María; García, Carlos Javier (2011) Glosario bilingüe de matemáticas, Madrid, Visión Libros.

Castro, Gilberto (2014) “El léxico de la medicina: usos metafóricos y metonímicos", Káñina, Revista de Artes y Letras de la Universidad de Costa Rica, XXXVIII, 65-71, DOI: 10.15517/RK. V38I3.16451 (última consulta: 03/04/21).

Сног, В. С.K. \& PAк, А.W. P. (2006) “Multidisciplinarity, interdisciplinarity and transdisciplinarity in health research, services, education and policy: 1 . Definitions, objectives, and evidence of effectiveness", Clinical and Investigative Medicine, 29(6), 351-364.

Cuadrado, Georgina; Argüelles, Irina; Durán, Pilar; Gómez, María José; Molina, Silvia; Pierce, Joana; Robisco, María del Mar; Roldán, Ana; Úbeda, Paloma (2016) Diccionario bilingüe de metáforas y metonimias científico-técnicas. Ingeniería, arquitectura y ciencias de la actividad fisica, New York, Routledge.

Cuartero, Juan Manuel (2002) “'Significado léxico' y ‘significado gramatical' en las gramáticas del español moderno", Boletín de la Sociedad Española de Historiografía Lingüística, 3, 43-78.

Cuéllar, María del Carmen \& Villa, Jeannette (1997) “Empleo metafórica y discurso de especialidad", Thélème: Revista complutense de estudios franceses, 11, 239-247. 
Derrida, Jacques (1966) “La structure, le signe et le jeu dans le discours des sciences humaines", Conferencia pronunciada en el Coloquio Internacional de la Universidad Johns Hopkins (Baltimore) sobre Los lenguajes críticos y las ciencias del hombre, recuperado de https://redaprenderycambiar.com.ar/derrida/frances/ structure.htm (última consulta: 03/04/21).

Díez de Revenga, Pilar (2003) “Lengua poética y lengua técnica: creación y ciencia", ELUA, 17, 263-272, recuperado de https://rua.ua.es/dspace/bitstream/10045/6176/1/ELUA_17_14.pdf (última consulta: 03/04/21).

Drożdż, Stanisław; Oświ@cimka, Pawę; Kulig, Andrzej; Kwapień, JarosŁaw; Bazarnik, Katarzyna; Grabska-GradzińsKa, Iwona; Rybicki, Jan y Stanuszek, Marek (2016) “Quantifying origin and character of long-range correlations in narrative texts", Information Sciences, 331, 32-44.

Duque, María del Mar (1999) “Orígenes, definición y características de la escritura científico-técnica en inglés", Acta, 14, 1120, recuperado de https://www.acta.es/medios/articulos/comunicacion_e_informacion/013009.pdf (última consulta: 03/04/21).

Elizondo, Emilia (2002) “El lenguaje figurado en los textos científico-técnicos: una reflexión sobre la teoría de la traducción y algunas propuestas prácticas", Universidad Nacional, recuperado de https://www.mogap.net/pmt/emiliaelizondo.pdf (última consulta: 03/04/21).

Eurrutia, Mercedes (2003) “Formación indirecta de la terminología técnico-científica: alusiones, imágenes y metáforas", en I. Iñarrea y M.J. Salinero (eds.), El texto como encrucijada: estudios franceses y francófonos, La Rioja, Servicio de Publicaciones de la Universidad de La Rioja, 367-380.

Funes, Digna Emérita (2013) La transformación retórica del texto científico en texto literario cuento como estrategia didáctica para fortalecer las competencias genéricas de comunicación escrita, análisis y sintesis, definidas en el perfil profesional de egreso del profesorado en la enseñanza del español. Tesis de Maestría de la Universidad Pedagógica Nacional Francisco Mozarán. 
Galán, Carmen (2001) "La ciencia con metáfora”, Anuario de estudios filológicos, 24, 123-136.

García, Mónica; Algas, Luís Antonio; Espinosa, Adrián Iven; Frómeta, Adonis; Chávez, Edilberto (2013) “La construcción de textos científicos en el ámbito de la investigación”, Multimed, 17(4), 1-14, recuperado de https://www.medigraphic.com/pdfs/multimed/mul-2013/mul134p.pdf (última consulta: 03/04/21).

Kedrov, Bonifati M. \& Spirkin, Alexander (1968) La ciencia, México D.F., Grijalbo.

Lakoff, George \& Johnson, Mark (1999) Philosophy in the Flesh. The Embodied Mind and its Challenge to Western Thought, New York, Basic Books.

Lakoff, George (2009) "The neural theory of metaphor", The Cambridge Handbook of Metaphor and Thought (ed. Raymond W. Gibbs, Jr.), New York, Cambridge University Press, 17-38.

LApesa, Rafael (2008) Introducción a los estudios literarios, Madrid, Cátedra.

Llácer, Eusebio \& Ballesteros, Fernando (2012) “El lenguaje científico, la divulgación de la ciencia y el riesgo de las pseudociencias", Quaderns de Filologia. Estudis Lingüístics, 17, 51-67, recuperado de https:/ojs.uv.es/index.php/qfilologia/article/ view/3373 (última consulta: 03/04/21).

Locke, David (1997) La ciencia como escritura, Valencia, Frónesis Cátedra Universitat de Valencia.

Lyotard, Jean-François (1979) La Condition Postmoderne. Rapport sur le savoir, Paris, Les éditions de minuit.

Maestro, Jesús G. (2014) Contra las Musas de la Ira. El Materialismo Filosófico como Teoría de la Literatura, Oviedo, Pentalfa.

Maestro, Jesús G. (2020) "Sobre la imposibilidad de razonar científicamente dentro de la Universidad actual", Youtube, recuperado de https://www.youtube.com/watch?v=2lq2nS0drvg (última consulta: 03/04/21).

Mancho, María Jesús (2005) “La divulgación científica y sus repercusiones léxicas en la época del Quijote", Panace@. Boletín de Medicina y Traducción, vol. VI (21-22), 285-298. 
Mardones, José María (2001) Filosofía de las ciencias humanas y sociales. Materiales para una fundamentación científica, Barcelona, Anthropos.

Martínez, Juan Antonio \& Myre, Annette (2009) Diccionario de expresiones y locuciones del español, Madrid, Ediciones de la Torre.

Martínez, Yaiza (2016) "Detectan fractales en las grandes obras de la literatura universal", Tendencias 21, 26 de enero de 2016, recuperado de https://www.tendencias21.net/Detectan-fractales-en-las-grandes-obras-de-la-literatura-universal_ a41872.html (última consulta: 03/04/21).

Mohler, Corey (2017) Cómics existenciales, Londres, Stirner.

Muñoz Rengel, Juan Jacinto (2020) Una historia de la mentira, Madrid, Alianza (versión ePub).

Neira, Hernán (1999) “Ciencia y metáfora: problemas de legitimación en las ciencias ambientales", Revista austral de ciencias sociales, 3, 159-166.

OngAY, Í̃̃IGo (2013) “¿Los límites de mi lenguaje son los límites de mi mundo? Wittgenstein y el alma de los brutos", El Catoblepas, 136, 1, recuperado de http://www.nodulo.org/ec/2013/ n136p01.htm (última consulta: 03/04/21).

Ostwald, Michael \& Vaughan, Josephine (2016) The Fractal Dimension of Architecture, Basilea, Birkhäuser.

Palma, Héctor (2008) Metáforas y modelos científicos. El lenguaje en la enseñanza de las ciencias, Buenos Aires, Libros del Zorzal.

Palma, Héctor (2015) “Ciencia y metáforas. Los viejos ruidos ya no sirven para hablar", Cuadernos de Neuropsicología, 9(1), 134-146, recuperado de http://www.cnps.cl/index.php/cnps/article/view/182/171 (última consulta: 03/04/21).

Pelc, Jerzy (1997) "Humanidades científicas vs. Humanidades literarias”, en R. Barriga, P. Martín, A. Rivas e Y. Rodríguez (eds.), Varia lingüística y literaria: 50 años del CELL: I. Lingüística, México, El Colegio de México, 265-276.

Pérez, Óliver (2010) Análisis de la significación del videojuego. Fundamentos teóricos del juego, el mundo narrativo y la enunciación 
interactiva como perspectivas de estudio del discurso. Tesis doctoral del Departament de Comunicació de la Universitat Pompeu Fabra.

Piaget, Jean (1970) “La situation des sciences de l'homme dans le système des sciences", en Tendances principales de la recherche dans les sciences sociales et humaines. Première partie: Sciences sociales, Paris, Unesco, 1-65.

Picardo, Osvaldo (2018) Colgados del lenguaje. Poesía en las ciencias, Rosario, Baltasara.

Quine, Willard (2013) Word and Object, Massachusetts, MIT Press.

Ramírez, Verónica \& Leyton, Patricio (2017) “Andrés Bello y la difusión de la astronomía: educación y retórica científica", Asclepio. Revista de Historia de la Medicina y de la Ciencia, 69(2), 198, DOI: http://dx.doi.org/10.3989/asclepio.2017.21 (última consulta: 03/04/21).

Real Academia Española y Asociación de Academias de la Lengua Española (2018) Libro de estilo de la lengua española según la norma panhispánica, Madrid, Espasa.

Saldivia, Zenobio (2009) "La antigua tarea de ordenar y clasificar a las ciencias", Revista Universum, 24(1), 206-216, recuperado de https://scielo.conicyt.cl/scielo.php?script=sci_arttext\&pi$\mathrm{d}=$ S0718-23762009000100012\#8 (última consulta: 03/04/21).

Sánchez, Ana María (2000) La divulgación de la ciencia como literatura, México, Dirección General de Divulgación de la Ciencia.

Saussure, Ferdinand (2005) Cours de Linguistique Générale (eds. Bally y Sechehaye), Ginebra, Arbre d'Or.

Texidor, Raiza; Reyes, Daniel; Camejo, Digna (2012) “Sugerencias para mejorar el estilo de redacción de un artículo científico en las ciencias de la salud", Revista de Educación Médica Superior, 26(1), 112-120, recuperado de https://www.medigraphic. com/pdfs/educacion/cem-2012/cem1211.pdf (última consulta: 03/04/21).

TORRe, Norberto de LA (2003) Introducción a la teoría y práctica del discurso: conversación y texto, Universidad Autónoma de San Luis de Potosí, Editorial Universitaria Potosina. 
Trujillo, Ramón (2004) “El concepto de 'sentido figurado' en el DRAE y cuestiones afines", Archivo de filología aragonesa, vol. 59-60(1), 899-916.

Urrutia, Jorge (1976). “Evolución y crítica de la estilística (notas introductorias)", Cuadernos de investigación filológica, 2(2), 85-96.

Wilson, Deirdre \& Sperber, Dan (2004) "Relevance Theory", The Handbook of Pragmatics (eds. Laurence R. Horn y Gregory Ward), Oxford, Blackwell, 607-632, recuperado de http://www. dan.sperber.fr/?p=93 (última consulta: 21/07/21) 